Delta J. Sci. 2009, 33:1-9

GEOLOGY

\title{
Preconcentration of Bismuth in Water Samples Prior to Determination by Atomic Absorption Spectrometry
}

\author{
Wifky S. A. El-Naggar \\ Nuclear Materials Authority, P.O. Box: 530 El-Maadi, Cairo, Egypt \\ (Received: 15 Oct. 2008)
}

\begin{abstract}
The possibility to use sodium diethyldithiocarbamate( $\mathrm{Na}$-DDTC) for bismuth(III) concentrating by the micellar extraction at cloud point (CP) temperature and subsequent atomic absorption spectrometry (AAS) determination was investigated. Under the optimum conditions, preconcentration of $10 \mathrm{ml}$ of water sample in the presence of $0.05 \%$ non-ionic surfactant (NS) Triton X-114, $5 \times 10-5 \mathrm{M}$ sodium diethyldithiocarbamate at $\mathrm{pH} 6$ permitted the detection $8 \mu \mathrm{g} \mathrm{I}-1$ bismuth. The proposed method has been applied to the AAS determination of bismuth in water samples after cloud point extraction.

Keywords: Cloud Point, Bismuth, Flame Atomic Absorption Spectrometry, Water Samples
\end{abstract}

\section{Introduction}

Bismuth and its compounds are used in semiconductors, cosmetic preparations, medicine for the treatment of syphilis, peptic ulcers and dermatological disorders, alloys, metallurgical additives and in the preparation and recycling of uranium nuclear fuels [1]. As the use of $\mathrm{Bi}$ in medicine increases, it has spread in the environment and the chance of exposure of organism to $\mathrm{Bi}$ has increased [2]. As a heavy metal, the toxicity assumed for $\mathrm{Bi}$ is not definitively confirmed, although there is association with neopathy, asteoarpathy, gingivitis, stomatitis, colitis and hepatitis and cases of encephalopathy in France and Australia [3]. Determination of volatile trace elements such as bismuth, indium and lead in water is of great importance for pollution control [4]. Hence, the development of new methods for selective separation, concentration, purification and determination of $\mathrm{Bi}$ in sub-micro levels is still a challenging problem. Several methods have been developed for the determination of bismuth. These include hydride generation inductively-coupled plasma (HG-ICPAES) [5], electrothermal vaporization ICP mass spectrometry (ETV-ICP-MS) [6], atomic absorption spectrometry (AAS) [7,8], potentiometric stripping analysis (PSA) [9], anodic stripping voltametry $[10,11]$ and cathodic stripping voltametry (CSV) [12]. However, due to the presence of bismuth in environmental samples at low levels, its separation from other elements present and also the use of a preconcentration step is usually necessary. Conventional solvent extraction and separation of $\mathrm{Bi}$ in the presence of co-extracting ligands, such as bis(2,4,4,-trimethyl penthyl) monothio phosphinic acid [13], pyrrolidine dithiocarbomate [14], has attracted considerable attention. The disadvantages with liquid /liquid extraction include the use of large volumes of organic solvents, cumber some glassware and cost. Nevertheless, several other techniques for pre-concentration of $\mathrm{Bi}$ have been proposed, including preconcentration using $\mathrm{Mg}-\mathrm{W}$ cell electrodeposition [15], preconcentration with sodium di-n-propyl dithiophosphinate and activated carbon in a batch method, flow injection on-line two stage solvent extraction [16], flow 
injection on-line sorption preconcentration $[17,18]$ and solid phase extraction [1922]. The use of surfactants in analytical chemistry is providing many new possibilities $[23,24]$ separation/preconcentration based on cloud point extraction (CPE) is emerging as an important practical technique. The cloud point extraction technique is based on the fact most nonionic surfactants form micelles in aqueous solutions and become turbid when they are heated beyond a temperature called the cloud point temperature (tc). Above tc, the micellar solution separates into two phases: a surfactant-rich phase of small volume and a diluted aqueous phase, in which the surfactant concentration is close to the critical micellar concentration $(\mathrm{cmc})$. Any analyte solubilized in the hydrophobic core of the micelles will separate and become concentrated in the small volume of the surfactant-rich phase. The small volume of the surfactant-rich phase permits the design of simple, efficient, inexpensive extraction schemes that do not involve the use of toxic organic solvents. Accordingly, any species that interacts with the micellar system, either directly (generally hydrophobic organic compounds) or after a prerequisite derivatization reaction (e.g. metal ions after reaction with a suitable hydrophobic ligand) may be extracted from the initial solution and thus also be preconcentrated [23]. The aim of this work is to introduce a reliable method for determination of bismuth in water samples by flame atomic absorption spectrometry after preconcentration by the cloud point extraction technique.

\section{Experimental}

\subsection{Reagents}

The following reagents were used: Triton $\mathrm{X}-114$ from Fluka was used without further purification. A stock standard solution of $\mathrm{Bi}^{+3}$ at a concentration $1000 \mu \mathrm{g} \mathrm{ml}^{-1}$ was obtained by dissolving apporaite amount of bismuthoxychloride (Merck) in $1 \mathrm{M} \mathrm{HCl}$. Hydrochloric acid was obtained from Chem. Laba. A stock solution of $1 \times 10^{-2} \mathrm{~mol} \mathrm{l}^{-1}$ sodium diethyldithiocarbamate (Merck) was prepared by dissolving appropriate amounts of this reagent in ethanol. Work standard solutions were obtained by appropriate dilution of the stock standard solutions with methanol (Adwic). All reagents were of analytical grade.

\subsection{Apparatus}

A Thermo Electron Corporation- S series atomic absorption spectrometer with deuterium lamp background correction and a bismuth hollow cathode lamp (current, $10 \mathrm{~mA}$ and slit width, $0.5 \mathrm{~nm}$ ) was used for $\mathrm{Bi}$ determination at wavelength of $223.1 \mathrm{~nm}$. The operating conditions were those recommended by the manufacture, unless specified otherwise. The sample and the acetylene flow rates and the burner height were adjusted in order to obtain the maximum absorbance signal, while aspirating the analyte solution in methanol. Cloud point preconcentration experiments were performed using a thermostated bath (Büchi 462 ), maintained at the desired temperature and phase separation was assisted using a centrifuge (Janetzki T32c).

\subsection{Procedure}

For the CPE, aliquots of $10 \mathrm{ml}$ of a solution containing the analytes, $0.05 \%$ Triton $\mathrm{X}-114$ and $5 \times 10^{-5} \mathrm{M}$ sodium diethyldithiocarbamate buffered at a $\mathrm{pH} 6$ were kept in the thermostatic bath maintained at $60^{\circ} \mathrm{C}$ for $10 \mathrm{~min}$. Since the surfactant density is $1.07 \mathrm{~g} \mathrm{ml}^{-1}$ therefore, the surfactant-rich phase can settle through the aqueous phase. The phase separation was accelerated by centrifuging for $10 \mathrm{~min}$ at $3000 \mathrm{rpm}$. After cooling in an ice-bath, the surfactant-rich phase became 
viscous and was retained at the bottom of the tube. The aqueous phases can readily be discarded simply. To decrease the viscosity of the extract and allow its pipetting, $200 \mu \mathrm{l}$ of methanol was added to the surfactant-rich phase. The final solution was introduced into the FAAS by conventional aspiration. Calibration was performed against aqueous standards submitted to the same cloud point extraction procedure. A blank submitted to the same procedure described above was measured parallel to the samples and calibration solutions.

\section{Results and discussions}

\subsection{Optimization of variables}

\subsubsection{Effect of $\mathrm{pH}$}

The $\mathrm{pH}$ plays a unique role on metal-chelate formation and subsequent extraction, and is proved to be a main parameter for CPE. The effect of $\mathrm{pH}$ on the extraction recovery of $\mathrm{Bi}(\mathrm{III})$ is shown in (Fig.1). It can be seen that extraction was maximum for $\mathrm{Bi}(\mathrm{III})$ at $\mathrm{pH} 6$.

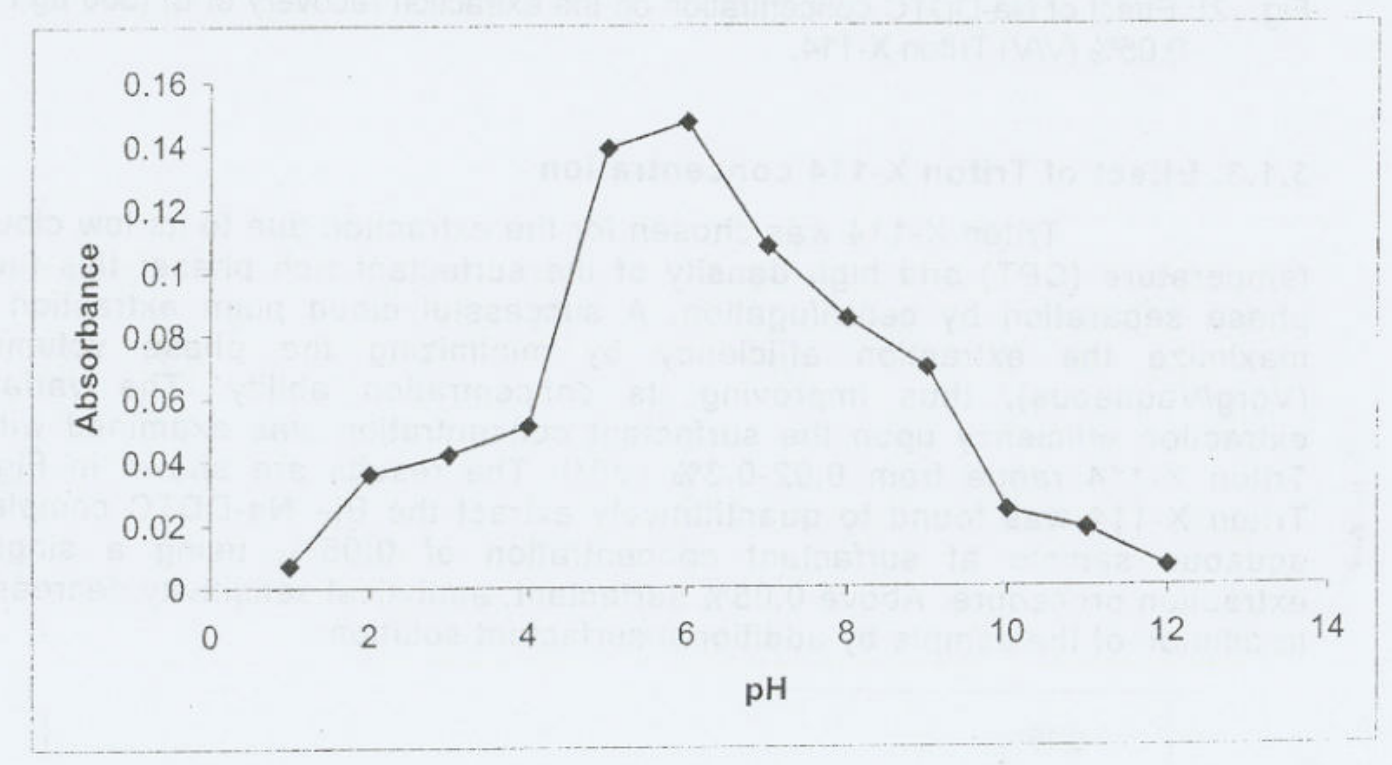

Fig. (1): Effect of pH concentration on the extraction recovery of $\mathrm{Bi}\left(500 \mu \mathrm{g} \mathrm{I}^{-1}\right) \cdot 5 \times 10-5 \mathrm{~mol} \mathrm{I}^{-1}$ (Na-DDTC), $0.05 \%$ (V/V) Triton X-114.

\subsubsection{Effect of Na-DDTC Concentration}

The effect of Na-DDTC concentration on the extraction recovery of $\mathrm{Bi}$ is shown in Fig. 2. For this study, $10 \mathrm{ml}$ of a solution containing $500 \mathrm{ng} \mathrm{ml}^{-1} \mathrm{Bi}$ in $0.05 \%$ (V/V) Triton $\mathrm{X}-114$ buffered at $\mathrm{pH} 6$ plus various amounts of Na-DDTC were subjected to the cloud point preconcentration process. For this $\mathrm{Bi}$ concentration, $\sim 100 \%$ extraction of $\mathrm{Bi}$ ion is achieved above a $\mathrm{Na}$-DDTC concentration of $4 \times 10^{-5} \mathrm{~mol} \mathrm{I}^{-1}$. A concentration of $5 \times 10-5 \mathrm{~mol} \mathrm{I-1} \mathrm{Na-DDTC}$ was chosen for subsequent experiments. 
W. S. A. El-Naggar, preconcentration of bismuth

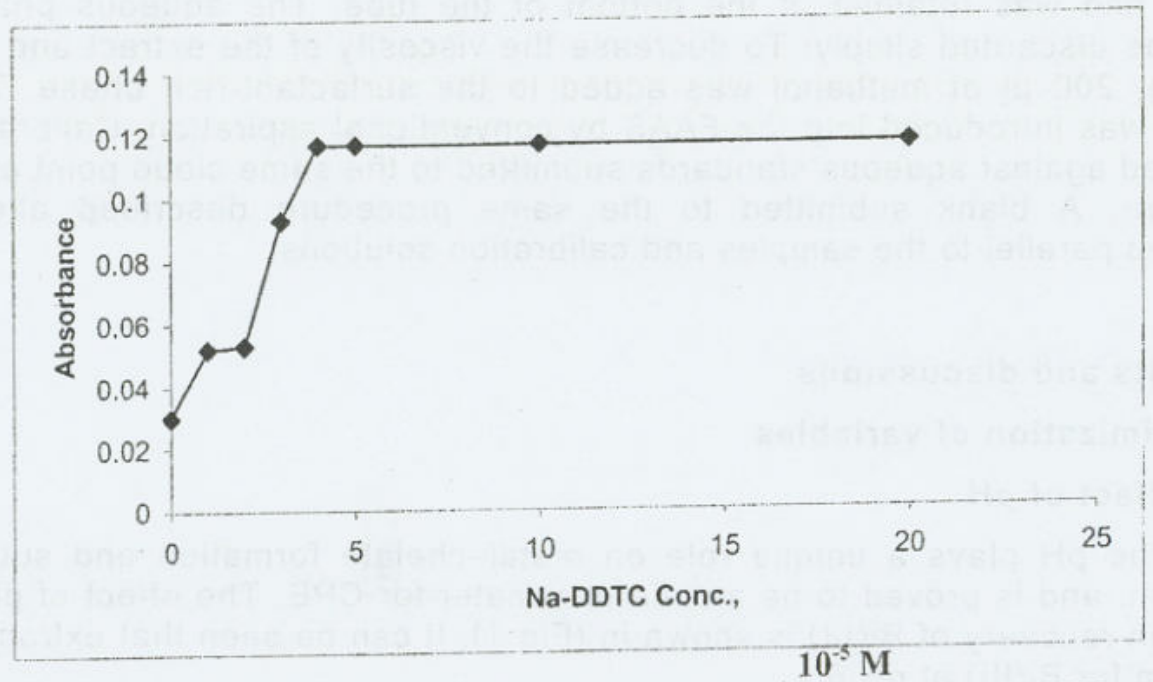

Fig. (2): Effect of Na-DDTC concentration on the extraction recovery of $\mathrm{Bi}\left(500 \mu \mathrm{g} \mathrm{I}^{-1}\right)$. $\mathrm{pH} 6$, $0.05 \%$ (V/V) Triton X-114.

\subsubsection{Effect of Triton $\mathrm{X}-114$ concentration}

Triton $\mathrm{X}-114$ was chosen for the extraction due to its low cloud point temperature (CPT) and high density of the surfactant rich phase; this facilitates phase separation by centrifugation. A successful cloud point extraction should maximize the extraction efficiency by minimizing the phase volume ratio (Vorg/Vaqueous), thus improving its concentration ability. The variation of extraction efficiency upon the surfactant concentration was examined within the Triton X-114 range from $0.02-0.3 \%$ (V/V). The results are shown in Figure. 3. Triton $\mathrm{X}-114$ was found to quantitatively extract the $\mathrm{Bi}-\mathrm{Na}$-DDTC complex from aqueous sample at surfactant concentration of $0.05 \%$, using a single step extraction procedure. Above $0.05 \%$ surfactant, analytical sensitivity decreased due to dilution of the sample by additional surfactant solution.

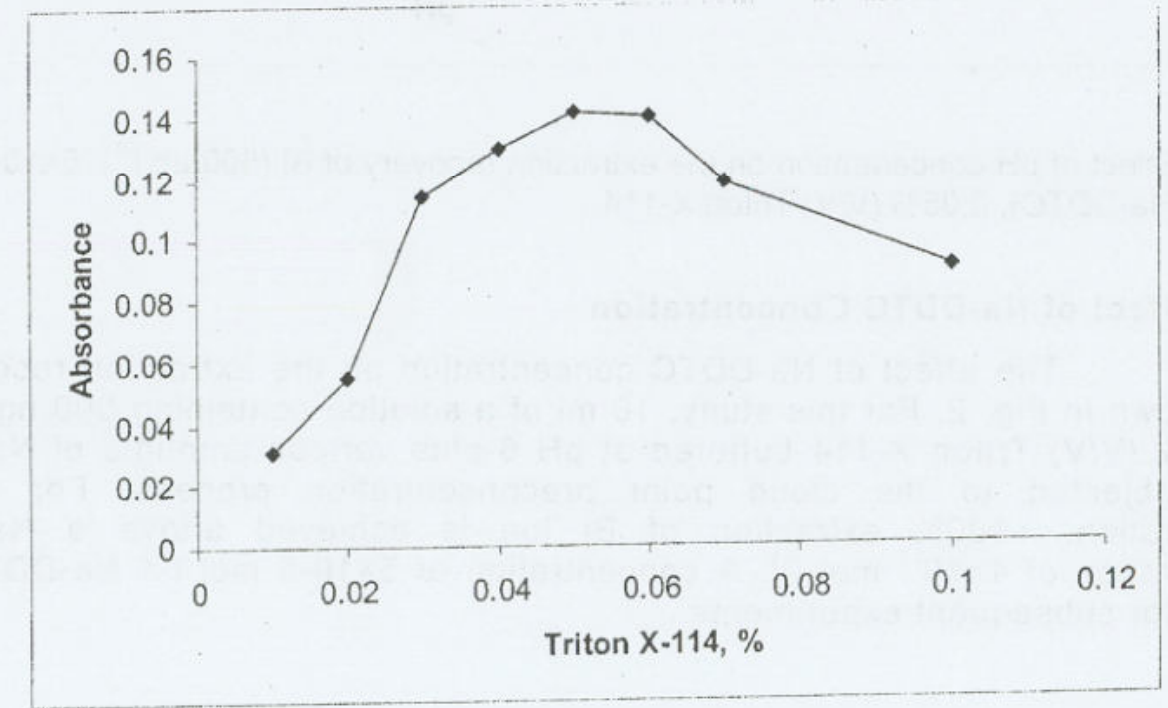

Fig. (3): Variation of the analytical signal of the bismuth as a function of Triton $X$ 114 concentration Conditions: $500 \mathrm{ng} \mathrm{ml}^{-1} \mathrm{Bi}, 5 \times 10^{-5} \mathrm{~mol} \mathrm{l-1} \mathrm{Na-DDTC,pH} 6$. 


\subsubsection{Effect of equilibration temperature}

The equilibration temperature above the cloud point was also optimized. It was desirable to employ the lowest possible equilibration temperature, which compromise completion of the reaction and efficient separation of the phases. The results illustrated in Fig. 4 show excellent recovery for equilibration temperature $60{ }^{\circ} \mathrm{C}$. Higher temperatures lead to the decomposition of $\mathrm{Na}-\mathrm{DDTC}$ and the reduction of extraction yield.

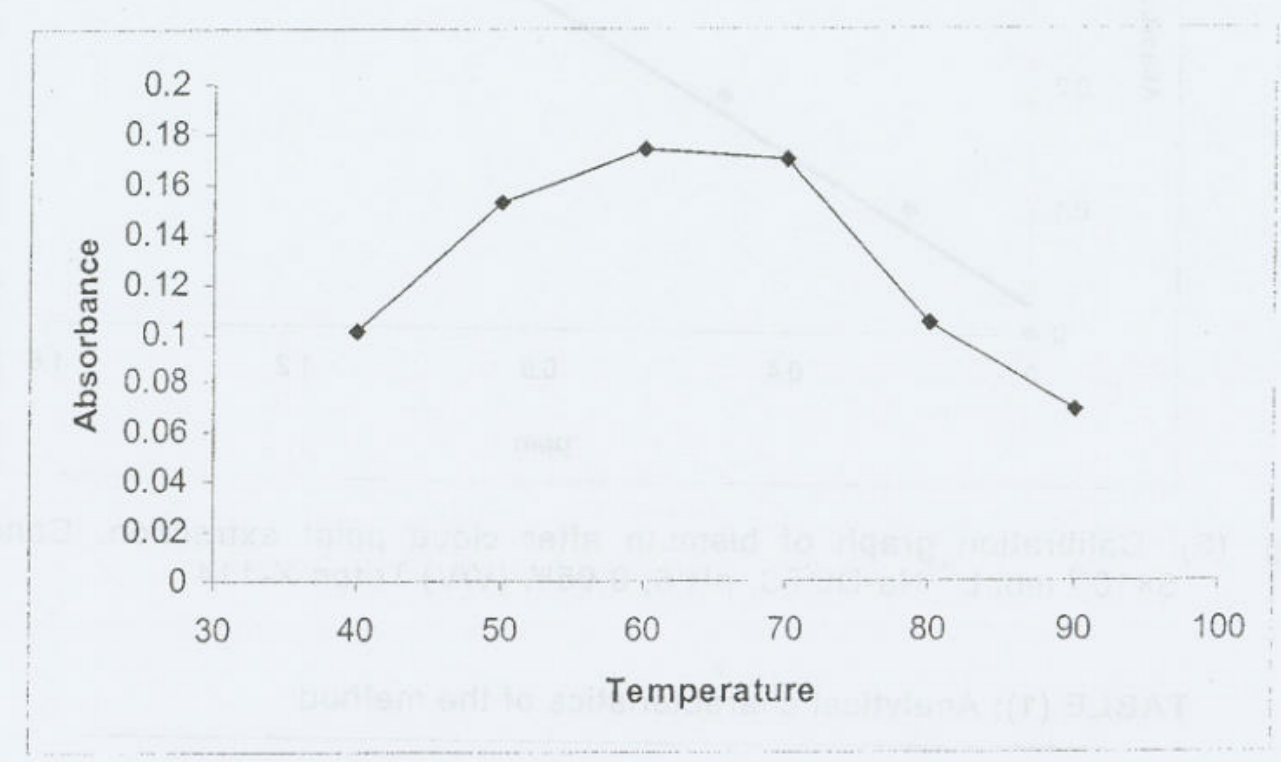

Fig. (4): Effect of equilibration temperature on the extraction recovery of bismuth. Conditions: $500 \mathrm{ng} \mathrm{ml}^{-1} \mathrm{Bi}, 5 \times 10^{-5} \mathrm{~mol}^{-1} \mathrm{Na}-\mathrm{DDTC}, \mathrm{pH} 6,0.05 \%$ (V/V) Triton X-114.

\subsection{Analytical characteristics}

Calibration graphs were obtained by preconcentrating $10 \mathrm{ml}$ of standard solution in the presence of $0.05 \%$ Triton $\mathrm{X}-114$ in a medium buffered at $\mathrm{pH} 6$. A volume of $200 \mu \mathrm{l}$ of the final solution was introduced into the flame by conventional aspiration via the sample aspiration tubing. In this case, linear relationships between the absorbance measured and the concentration of metal prepared for the calibration solution was obtained, Fig. 5 . Table 1 gives the calibration parameters, the relative standard deviation obtained for 6 analyte samples subjected to the complete procedure and the detection limits are given in table (1). It summarizes the analytical characteristics of CPE method. 
W. S. A. El-Naggar, preconcentration of bismuth

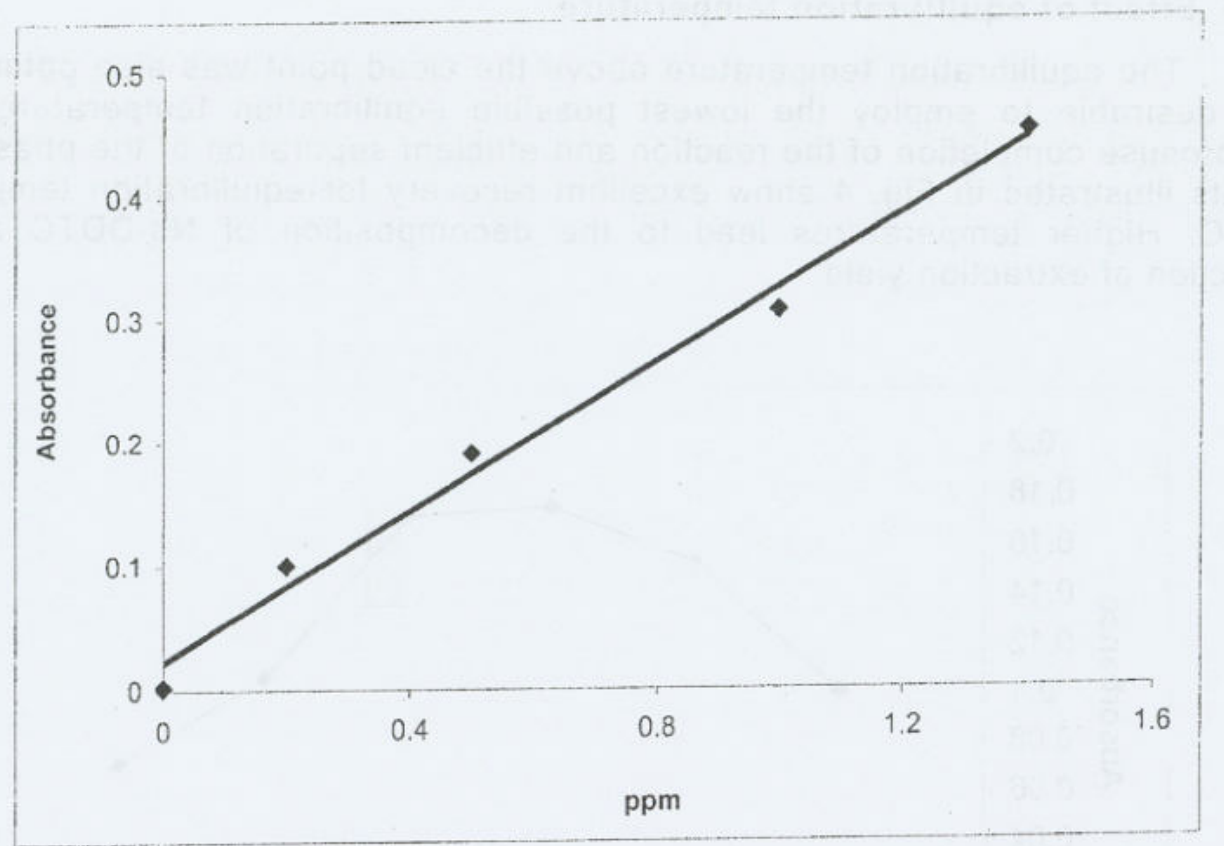

Fig. (5): Calibration graph of bismuth after cloud point extraction. Conditions: $5 \times 10^{-5} \mathrm{~mol} \mathrm{~L}^{-1} \mathrm{Na}-\mathrm{DDTC}, \mathrm{pH} 6,0.05 \%$ (V/V) Triton X-114.

TABLE (1): Analytical characteristics of the method

\begin{tabular}{|c|c|}
\hline Parameter & $\mathrm{Bi}$ \\
\hline Linear range $\left(\mu \mathrm{g} \mathrm{I}^{-1}\right)$ & $10-1400$ \\
\hline $\mathrm{C}^{\circ}\left(\mu{\left.\mathrm{g} \mathrm{i}^{-1}\right) \text { for } 0.0044 \text { absorbance }}^{a}\right.$ & 11 \\
\hline Slope $(\mathrm{m})\left(10^{-3}\right)$ & 0.3 \\
\hline Correlation coefficient $(r)$ & 0.989 \\
\hline R.S.D. $(\%)(n=6)^{b}$ & 7.8 \\
\hline $\operatorname{LOD}(\mu \mathrm{g} \mid-1)^{c}$ & 8 \\
\hline Enrichment factor ${ }^{d}$ & 23 \\
\hline
\end{tabular}

a $\mathrm{C}^{\circ}$, the characteristic concentration

b bismuth concentrations was $500 \mu \mathrm{g} \mathrm{l-1}$ which the R.S.D. was obtained.

c Limit of detection. Calculated as [(3S.D. of blank /m].

d Calculated as the ratio of slope of preconcentrated samples to that obtained without preconcentration.

\section{Application}

The proposed CPE-FAAS methodology was applied to the determination of $\mathrm{Bi}$ in several water samples. In order to validate the proposed method, recovery experiments were also carried out by spiking the water samples with amounts of $\mathrm{Bi}$ before any pretreatment. The solutions were analyzed using the standard additions 
calibration and the percentage recoveries were calculated. Table 2 shows the obtained results. The slopes of the standard additions graphs for water samples did not have any significant difference with that of calibration graph and also the corresponding detection limits for each water sample were found to be the same as that obtained from standard solutions. Therefore, we can conclude that there are no interferences from the sample matrices.

TABLE (2): Determination of bismuth in water samples by the developed procedure using Na-DDTC as a complexing agent.

\begin{tabular}{|c|c|c|c|}
\hline \multirow[t]{2}{*}{ Sample } & \multicolumn{2}{|c|}{$\mathrm{Bi}\left(\mu \mathrm{g} \mathrm{ml}^{-1}\right)$} & \multirow[t]{2}{*}{ Recovery (\%) } \\
\hline & added & found & \\
\hline \multirow[t]{2}{*}{ Tab water } & - & $N D^{\circ}$ & - \\
\hline & 0.5 & 0.49 & 98 \\
\hline \multirow[t]{2}{*}{ Well water b } & - & 0.0155 & - \\
\hline & 0.5 & 0.5158 & 100.1 \\
\hline
\end{tabular}

\section{Conclusions}

We have proposed the use of cloud point extraction as an alternative method for the Preconcentration of $\mathrm{Bi}$ as a prior step to its determination by FAAS. The method allows the determination of low levels of $\mathrm{Bi}$ by FAAS. The methodology offers a simple, rapid, sensitive, low cost, good extraction efficiency and lower toxicity than those using organic solvents. Environmental pollution is limited to a small amount of surfactant. The method improves the limit of detection. The proposed method can be applied for the determination of bismuth in water samples. 
W. S. A. El-Naggar, preconcentration of bismuth

\section{References}

[1] D.W. Thomas, in: E. Merian (Ed.), Metals and Their Compounds in the Environment, VCH, Weihneim, 1991,pp. 789-801.

[2] S.I. Itoh, S. Kaneco, K. Ohta, T. Mizuno, Anal. Chim.Acta 379 (1999) 169.

[3] G.G. Briand, N. Burford, Chem. Rev. 99 (1999) 2601.

[4] O. Acara, A. R. Türker, Z. Kılıc, Spectrochimica Acta Part B 55, 2000,16351641

[5] A. Morrow, G. Witshire, A. Huvsthous, At. Spectrosc. 18 (1997) 23.

[6] M.V. Hinds, D.C. Gregoie, E.A. Ozaki, J. Anal. At. Spectrom. 12 (1997) 131.

[7] S. Tokalioglu, S. Kartal, L. Elci, Microchim. Acta 127 (1997) 281.

[8] G.E.M. Hall, A.T. Maclaurin, J.C. Pelchat, G. Gauthier, Chem. Geol. 137 (1997) 79.

[9] P. Ostapczuk, Anal. Chim. Acta 273 (1993) 35.

[10] R.D. Ye, S.B. Khoo, Electroanalysis 9 (1997) 481.

[11] C.M. Wang, Q.Y. Sun, H.L. Li, Electroanalysis 9 (1997) 645.

[12] T. Ferri, S. Paci, R. Morabito, Ann. Chim. 86 (1996) 595.

[13] S.G. Sarkar, P.M. Dhadke, Sep. Purif. Technol. 15 (1999) 131.

[14] J.M. Lo, Y.P. Lin, K.S. Lin, Anal. Sci. 7 (1991) 455.

[15] S.I. Itho, S. Kaneco, K. Ohta, T. Mizuno, Anal. Chim. Acta 379 (1999) 169.

[16] J. Wang, E.H. Hansen, Anal. Lett. 33 (2000) 2747.

[17] E. Ivanova, X.P. Yan, F. Adams, Anal. Chim. Acta 354 (1997) 7.

[18] M.B.O. Giacomelli, E.M. Ganzarolli, A.J. Curtius, Spectrochim. Acta Part B 55 (2000) 525.

[19] S. Moyano, J.A. Gasquez, R. Olsina, E. Marchevsky, L.D . Martinez, J. Anal. At. Spectrom. 14 (1999) 259.

[20] E. Vassileva, L. Proinova, K. Hadjiivanov, Analyst 121 (1996) 697.

[21] R. Kocjan, M. Garbacka, Sep. Sci. Technol. 29 (1994) 799.

[22] J.B.B. Silva, M.B.O. Giacomelli, A.J. Curtius, Analyst 127 (1999) 1249.

[23] J.L. Manzoori, A. Bavili-Tabrizi, Microchem. J. 72 (2002) 1.

[24] Q. Fang, M. Du, C.W. Huie, Anal. Chem. 73 (2001) 3502. 


\section{الملذص المعبىى}

تركيز عنصر البزموث في عيذات المبياه قبل تعبيزه بواسطة جهاز الامنصاص الذرى الطيفي

$$
\text { وفقي السيد عبدالهادي الذجار }
$$

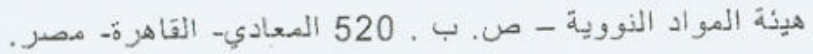

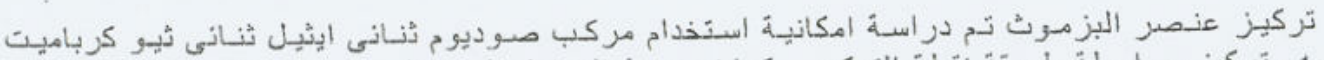

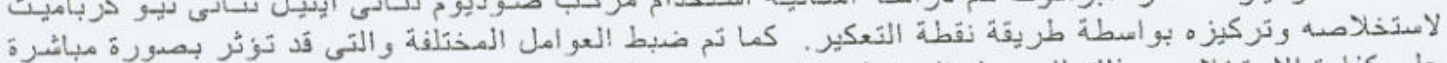

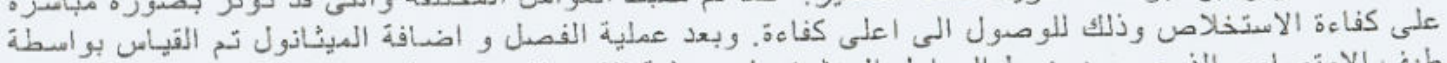

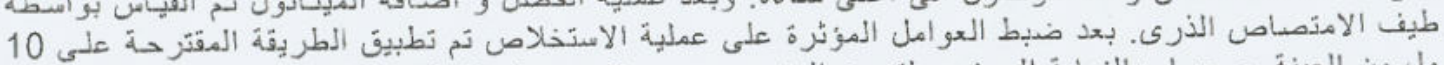

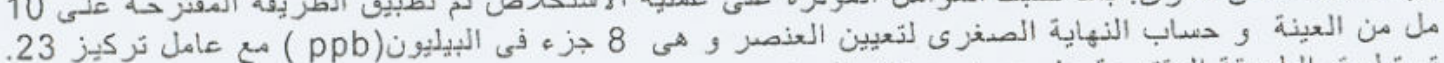

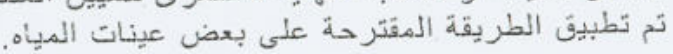

